\title{
Discussion about the Lack of Contemporary College Students’ Humanities Accomplishment and Improving Methods
}

\author{
Xianhua Meng \\ Feixian College, Linyi University, Feixian, Linyi, Shandong, China (mengxh18@163.com)
}

\begin{abstract}
Contemporary college students are playing more and more important roles in the future development of China. Naturally, the requirement of the humanistic literary for the college students will become higher and higher. However, the current social accomplishment of college students presents a weak trend, which status is worrying. In this paper, how to improve the contemporary college students' humanities cultivated manners is discussed through taking about the lack of college students' humanities cultivated manners accomplishment. To improve college students' humanities accomplishment education is around the corner, which not only the basic task of education, but also the inevitable trend of the development of college and universities.
\end{abstract}

Keywords - college students, humanities cultivated manners, deficiency, improvement

\section{刍议当代大学生人文素养的缺失和提升}

\author{
孟宪华 * \\ 临沂大学费县分校，费县，临沂，山东，中国
}

摘 要 大学生在中国未来的发展道路上起着越来越重要作用, 我们对于当代大学生的人文素养要求自然而然的也会越来越高。但 是, 当下社会大学生的素养逐渐呈现出弱化趋势, 状况令人担忧。本文通过对大学生人文素养相对缺失的现状分析, 进而就如何提升 当代大学生人文素养进行了探讨。提升大学生人文素养, 不仅是高校教育的根本任务, 也是高校发展的必然趋势。

关键词 大学生, 人文素养, 缺失, 提升

近年来，随着社会经济的迅速发展，我国的高等院 校无论在数量上还是在质量上都取得了长足的进步, 素 质教育也越来越受到人们的重视。但在世界科技革命和 知识经济浪潮的冲击下，当代大学生的人文素养却逐渐 呈现出弱化趋势。一些大学生不同程度地存在政治信仰 迷茫、理想信念模糊、社会责任感缺乏、诚信意识淡薄、 艰苦奋斗精神淡化、价值取向扭曲、团结协作观念较差、 心理素质较差等一系列问题。大学生素质教育弱化, 不 仅影响到我国高等教育人才培养的质量, 同时还会严重 阻碍我国社会主义现代化的发展进程。我们要实现中华 民族的伟大复兴, 实现中国梦, 不仅经济要发展, 科技 要进步, 人文精神更需要回归。这就要求担负着培养国
家高素质人才使命的高校不但要培养大学生过硬的专 业知识和技能, 还要注重其人文素养的提升。

\section{1. 大学生人文素养缺失的现状}

人文素养是人类文明发展程度的重要标志, 它是人 类的一种高度自我关怀, 维护和关注人类的尊严、价值、 命运, 它为人类的发展提供内在动力和方向保证。然而 我们的高校办学在过去较长一段时间, 受市场需要和大 学生就业形势的不乐观影响, 过分强调了人才的专业教 育, 严重忽视了对大学生人文素养的教育, 忽略了高校 教育的根本目的一一人的全面发展。现在大学生们关注 更多的是显性的专业知识的教育, 对于隐性的人文素养 却关注不够, 甚至严重缺失, 主要存在以下问题。

\footnotetext{
* Meng Xianhua (1979-), male, Chinese lecturer of Linyi University Feixian College, Master
} 


\section{1 人生追求更加务实、功利}

我国社会正处于大变革时期, 加之大学生又常因心 智不成熟而易产生出困惑乃至是迷茫, 价值观和人生追 求上具有很强的功利性、目的性。相当一部分大学生认 为上大学的目的就是为了拿高文凭, 找好工作; 他们在 择业时往往也是选择一些大城市, 或者一些高收入的行 业; 在人际交往时也习惯抱着实用主义的态度, 甚至包 括与老师交往也带有很重的务实考虑; 在道德责任意识 方面, 心态浮躁, 对社会的终极关怀表现淡漠。他们重 利轻义, 重物质轻精神, 缺乏责任意识和义务观念。不 少大学生对国家和集体的事漠不关心, 认为“事不关己, 高高挂起”! 对他人、社会缺乏爱心和奉献精神, 人际 关系淡漠。他们拥有很强的自我意识, 自我倾向明显, 遇事斤斤计较, 不会换位思考, 不会体谅他人。在人格 上缺乏独立性, 缺乏独立思考和判断能力, 缺乏应对各 种挫折的能力和心理素质。

\section{2 人文知识匮乏, 人文精神缺失}

近年来, 受就业形势的影响, 有相当一部分大学生, 尤其是理工科学生对人文社会科学等非功利的学科知 识缺乏兴趣。即使是一些人文专业的学生, 也仅仅停留 在人文知识学习的层面, 把 “修养” 放到了一边, 而忘 却了人文教育的根本目的是培养人文精神, 培养对社 会、对人民、对自己从事的事业高度负责的一代新人, 全面发展的人。他们对中华民族传统文化知之甚少, 对 世界文化的了解远远不够。这使得他们精神空虚, 情感 脆弱, 心胸狭险, 目光短浅, 他们认识不到人文知识的 隐性功效, 他们认为人文知识是毫无用处的, 都是些空 洞的的不切实际的大道理!

\section{3 传统文化受到漠视, 民族归属感淡化}

中国文化的其中一个最为重要的组成部分就是传 统文化。传统文化是一个民族得以延续的精神基因, 是 民族凝聚力的重要基础, 是培育民族心理、民族个性、 民族精神的摇篮。对中国的传统文化知之甚少, 不珍惜 中国的传统文化的人, 不仅是数典忘祖, 也是一个不合 格的中国人。现在的大学校园里, 一些大学生受西方文 化的影响, 盲目推崇西方文化与西方的生活方式, 他们 看好莱坞大片, 听欧美流行音乐, 嚼薯片, 过情人节、 圣诞节……中国许多优秀传统文化典籍却鲜有人问津, 他们对中国传统的清明、端午、中秋等节日兴趣日趋淡 漠。他们无法体会人文教育对于净化心灵, 陶冶情操的 作用，他们缺乏历史的观念，民族的认同感。
1.4 心理方面存在不少的问题和缺陷

由于现在生活环境的好转, 以及越来越多的独生子 女进入大学校园, 当代大学生在心理方面的问题已经引 起了社会广泛的关注。这些问题往往表现为大学生人际 交往能力不高, 交际困难; 存在学习和就业压力; 存在 角色转换与适应障碍; 对网络产生过于强烈的依赖性; 存在人格养成缺陷等。他们缺乏意志力, 情绪不稳定, 言行不理性, 极易冲动偏激, 对挫折和压力缺乏应有的 承受力, 认为生活无目的、无价值、无意义, 心态失衡 甚至个性扭曲。

\section{2. 当代大学生人文素质提升的有效途径}

\section{1 高校要强化现代人文教育理念}

加强大学生人文素养的培育与提升, 前提是教育者 应转变以往教育理念。以本科教育为例, 目前我国大学 的人文教育主要落实为大学一年级和二年级阶段的制 度化通识教育。要改变这种现状, 首先就是强调大学本 科通识教育的重要性, 需要重新界定中国大学本科阶段 的教育目的和培养目标, 改变以往狭险的本科专业化培 养模式, 探索大学本科教育模式的转型问题。高校应该 立足于学生长远的、终身的发展, 树立与现代教育特点 相符合的以人为本的教育理念, 要立足于人的全面发 展, 注重提升和完善人的理想、情操、道德水平。让大 学生们能在更高的境界与层次上正确把握和实现他们 的自身价值, 帮助他们摆脱急功近利的思想, 树立远大 的理想和信念, 脚踏实地、艰苦奋斗, 关爱他人, 关爱 社会。同时, 高校还要改变过去过于一味强调专业知识 的做法, 从思想理念上将大学生的人文素质教育摆在与 专业教育同等甚至更高的位置, 加大对大学生的人文素 养教育投入力度。

\section{2 建立凸显人文精神的教育机制}

深入培养大学生人文精神, 高校就应该把各专业学 科的育人作用充分重视发挥出来, 要寓人文精神于专业 课程的教学之中, 要通过教授专业课程, 让学生从中体 会和感受人生的内涵, 从而内化为自身的素质。同时, 高校还要利用各种有利条件, 尽可能开发学校的人文课 程, 增加人文课程的设置。高等院校应改变目前大学人 文课程的设置不合理的现象, 提高人文教育的地位, 以 必修课的形式, 着重进行公共基础理论教育。也可以采 取各种措施鼓励相关教师开设人文学科选修课程, 扩大 人文学科对学生的影响力和吸引力。也可以开设人文大 家讲坛, 定期邀请一定数量的国内外有影响的人文大家 
来校开展专题讲座。坚持面向学校全体学生开设国学、 普通话、书法、基础写作等人文素质教育课, 利用网络 资源定期开展文章、音乐、书画等人文经典的赏析, 让 学生在丰富多彩的课余生活中感受人文并最终热爱人 文。

\section{3 发挥教育者的榜样作用}

榜样的力量是无穷的, 教育者的示范作用对学生人 文素质的培养起着潜移默化的重要作用。伟大的思想、 高尚的情操、美好的品德、良好的作风, 都可以通过一 个具体的形象得到生动的体现, 把抽象高深的道德标 准、政治理论概念人格化, 一切美好的东西都能在榜样 身上看得见摸得着。高校教师的人文素质直接影响高校 学生的人文素质质量, 教师素质高低是高校人文素质教 育能否成功的关键。教师的职业素养要求一名合格的教 师应当具有渊博的人文知识, 具备良好的人文素养。教 师要有提高自身人文素养的自觉性和责任感, 要不断研 习优秀传统文化, 拓展知识领域, 构建自己的知识体系, 要真正的教书育人, 成为学生敬仰和标榜的良师。本着 对国家和人民高度负责的态度, 各高校要严把教师选任 入口关, 让专业知识渊博和人文素养高的教师充实到高 校教师队伍来, 最大限度地提高教师从事人文教育的积 极性与主动性。

\section{4 营造浓郁的校园人文环境}

人文素质教育离不开校园人文环境, 只有在外部营 造良好的人文环境, 才能为人文素质教育提供沃土。高 校应首先积极搭建人文环境平台, 让学生在学习、生活 中得到提高, 其次应营造浓郁的人文学习氛围, 让学生 在潜移默化中得到提高。校园文化环境是全方位的, 涵 盖学生学习、生活的方方面面, 只有让学生在这种氛围 中熏陶、感染, 才能内化为自身的人文素质, 才能为将 来事业发展提供不竭动力。大学生良好人文素养的培育 与提升与每一个人都息息相关, 我们要充分认识到这项 工作的重要意义, 就应该人人参与, 为高素质人才的成 长提供肥沃的土壤和优良的环境。在政府和社会各界力 量的配合下, 大学校园必将成为莘莘学子增加学识、提 升人文素养的理想场所, 大学生身处其中, 必将学会感 悟、思考, 从而提升素养, 净化灵魂, 升华人格。如果 中国人和中国大学生能够具有充分的文化自觉, 如果中 国的大学牢牢地植根于中国文明的最深处, 那么, 即使 今天中国的大学仍然很不理想, 但我们有理由期望, 经
过一两代人的不解努力, 中国的大学作为伟大中国文明 的担纲者将会成长为伟大的大学。

大学生人文素养的高低不仅决定着大学生未来的 发展, 而且关系到国家和民族的前途命运。加强大学生 人文素质教育迫在眉睫, 这不仅是教育的根本任务, 也 是高校发展的必然趋势。大学生人文素养的提升是一项 复杂而又系统的工程, 需要全社会的关心和支持, 非一 朝一夕之功, 而是一个潜移默化, 长期起作用的过程, 必 须从实际出发, 急功近利, 一蹴而就是不现实的。高校要 认清形势, 调动一切积极因素, 努力提高大学生人文素 质, 为社会培养更多德才兼备的优秀毕业生, 为推进和 加快中国梦得以全面实现作出新的贡献。

\section{参考文献(References)}

[1] Mingxia Chen. Think about the Current Situation of College Students' Humanities Accomplishment and Countermeasures. Fujian Forum, 2013(8):188-191.

[2] Ting Xu. How to Train and Improve the Contemporary College Students' Humanities Cultivated Manners. Human Resource Management, 2014(2): 161-163.

[3] Haiying Feng. Think Back to the Shortage of College Students' Humanities Cultivated Manners. Consume Guide. EueatioSpace, 2007(3):125-126.

[4] Kangmei Ma, Zhenjiang Zheng. Research on the Current Situation of College Students' Humanities Accomplishment and the Potential Development Capacity. New Science, 2007(2): 55-60.

[5] Xiaoqin Zhang, Yongjiang Nie. Improving Routes of the Contemporary College Students’ Humanities Cultivated Spirit. Jiangsu Higher Education, 2014(1):129-130.

[6] Lei Zhao. Connotation and Promotion of the Humane Accomplishment of the College students. Journal of Chongqing University, 2002, 9(2):156-158.

[7] Guangjun Gong, The deficiency and Reformation of Contemporary College Students' Humanities Accomplishment. Journal of Chongqing vocational \&Technical Institute, 2007, 3, 16(2):37-40.

[8] Xiaolei Dong. The Current Situation of College Students' Humanities Accomplishment. Journal of Hubei University of Economics, 2013, 10(10): 127-128. 